\title{
Impact of Smoking on Mortality in 80-Year-Old Japanese from the General Population
}

\author{
Kiyoshi Fujisawa ${ }^{a}$ Yutaka Takata ${ }^{a}$ Takayuki Matsumoto ${ }^{c}$ Motohiro Esakic \\ Toshihiro Ansai $^{\mathrm{b}}$ Mitsuo lidac \\ Divisions of ${ }^{\mathrm{a}}$ General Internal Medicine and ${ }^{\mathrm{b}}$ Community Oral Health Science, Department of Health Promotion, \\ Science of Health Improvement, Kyushu Dental College, Kitakyushu, and ${ }^{\mathrm{C} D e p a r t m e n t}$ of Medicine and Clinical \\ Science, Graduate School of Medical Sciences, Kyushu University, Fukuoka, Japan
}

\section{Key Words}

Mortality, smoke-related $\cdot$ Old age, Japan

\begin{abstract}
Background: It is well known that cigarette smoking is the main health hazard in middle-aged people. However, data regarding smoking and health in old-aged people are limited, especially in the Japanese population. Objective: The present study aimed to investigate the influence of smoking on mortality in the elderly Japanese population. Methods: A cohort of 690 individuals of 80 years of age were categorized into 3 groups: non-smokers, ex-smokers and current smokers. The adjusted mortality after 4 years was compared among the 3 groups. The possible influence of smoking status on the cause of death was also investigated. Results: The overall mortality was significantly higher in males [relative risk (RR): 2.3, 95\% confidence interval (Cl): 1.0-5.2] and females (RR: $4.2,95 \% \mathrm{Cl}$ : 1.9-9.5) in the current-smoker group than in the non-smoker group. The risk of any-cause mortality in the ex-smoker group was not statistically different from that in the non-smoker group. In males, current smokers died of cancer more frequently than non-smokers (RR: 10.7, 95\% Cl: 1.3-90.8). Cardiovascular disease was a significant cause of death in female current smokers (RR: 5.2, 95\% Cl: 1.6-16.9). This difference in mortality was not observed between groups of non-smokers and ex-smokers of both
\end{abstract}

genders. In male smokers, there was a positive relationship between the daily amount of consumed cigarettes and overall mortality. Conclusion: Smokers should be encouraged to stop smoking, since habitual smoking increases the risk of mortality even in old age.

Copyright $\odot 2008$ S. Karger AG, Basel

\section{Introduction}

Smoking is a major health hazard, and a number of reports have demonstrated the habit to be a strong risk factor for all causes of morbidity and mortality [1-3]. This is especially the case for lung cancer [3-5], head and neck cancer [6], oesophageal cancer [4], cardiovascular disease [7-10] and chronic obstructive lung disease [11, 12].

Pelkonen et al. [13] reported that the cessation of smoking reduced the deterioration of pulmonary func-

Other collaborators: Kazuo Sonoki, Shuntaro Kagiyama and Ikuo Nakamichi (Division of General Internal Medicine, Kyushu Dental College, Japan); Shuji Awano, Inho Soh, Tomoko Hamasaki, Akihiro Yoshida and Tadamichi Takehara (Division of Community Oral Health Science, Kyushu Dental College, Japan); Akira Sogame (Keichiku Office for Health, Human Services and Environmental Issues, Japan); Naoko Shimada (Kitakyushu Public Health and Welfare Bureau, Fukuoka, Japan).

\section{KARGER}

Fax +41613061234 E-Mail karger@karger.ch www.karger.com
(C) 2008 S. Karger AG, Base

0304-324X/08/0544-0210\$24.50/0

Accessible online at:

www.karger.com/ger
Kiyoshi Fujisawa, MD

Department of General Internal Medicine, Kyushu Dental College

Manazuru 2-6-1, Kokurakita-ku

Kitakyushu City 803-8580 (Japan)

Tel. +81 93582 1131, Fax +8193582 0592, E-Mail yritsuko@intmed2.med.kyushu-u.ac.jp 
tion in a middle-aged Finnish population. Enstrom [3] investigated the influence of smoking status on all causes of mortality among middle-aged US veterans and demonstrated that a gradual improvement in the mortality rate only occurred in long-term quitters. It has thus been indicated that the cessation of smoking is mandatory for the recovery of unfavourable physical conditions in middle-aged smokers. However, whether the cessation of smoking can improve life expectancy in the elderly has not been adequately investigated to date. Therefore, we analysed the influence of smoking status on mortality in a cohort of elderly Japanese.

\section{Subjects and Methods}

\section{Study Subjects}

The present study is part of a Japanese community-based survey referred to as the 8020 Data Bank Survey. The 8020 Data Bank Survey was designed to accumulate baseline data on the physical and dental conditions of healthy individuals aged 80 years, and to promote the concept of having at least 20 original teeth at that age. Since the survey was started in April 1998, individuals who were born in 1917 were recruited from the resident registers of 9 districts (Munakata City, Yukuhashi City, Buzen City, Tobata Ward in Kitakyushu City, Katsuyama Town, Toyotsu Town, Tsuiki Town, Kanda Town and Shinyoshitomi Village) in Fukuoka prefecture. We initially mailed a letter of invitation to 1,282 individuals aged 80 and contacted non-responders by mail or phone 1 month later. Four hundred and fifty-five individuals refused the invitation, and 130 individuals were excluded from the survey because they had been admitted to medical institutions at the time of the invitation. Consequently, 697 ambulatory individuals with well-preserved activities of daily living (ADL) accepted the invitation to participate in the survey.

Among 697 participants, 7 individuals were excluded because their smoking habit was obscure. The remaining 690 participants ( 275 males and 415 females) were enrolled as a cohort of the present study. The study protocol was performed in accordance with the Declaration of Helsinki, and was approved by the Human Investigations Committee of Kyushu Dental College. Informed consent was obtained from each participant after the details of this study protocol had been explained.

\section{Demographic Data at Baseline}

In April 1998, baseline clinical data were collected in a face-toface interview using a medical questionnaire; blood tests were taken and measurements of height, weight and blood pressure were recorded. The medical questionnaire included enquiries with regard to smoking status, alcohol consumption and ADL, in accordance with our previous reports $[14,15]$. ADL were categorized into either independent or dependent ADL, with the latter consisting of people who required physical support in their daily activities. With regard to alcohol consumption, a drinker was defined as a person who consumed alcohol more than 3 times per month; others were regarded as non-drinkers. Blood tests included serum concentrations of total cholesterol and fasting blood glucose.
Mortality and Cause of Death

With the permission of the Fukuoka Prefecture Government, the mortality during a 4-year period after the baseline was assessed by reviewing registers of residents in March 2002. In subjects deceased before March 2002, the cause of death was taken from the information registered at the Public Health Centre of each district.

\section{Classification of Smoking Status}

Smoking status was classified into 3 categories: non-smoker, ex-smoker and current smoker. Non-smokers were defined as those who had never smoked. Current smokers were defined as those who were habitual smokers at the time of baseline assessment. Other individuals were defined as ex-smokers. Precise information on the amount of cigarettes consumed was obtained from the medical questionnaire that was filled out during the face-to-face interview. Ex-smokers were also asked the time of cessation.

\section{Statistical Analysis}

The continuous data were expressed as means \pm SD, and compared among the groups using Student's t test. The qualitative data were expressed as frequencies and were compared using the $\chi^{2}$ test. The cumulative survival rate was calculated by the Kaplan-Meier method, and compared among the groups by the logrank test. The Cox proportional hazards model was used to calculate the relative risk (RR) and 95\% confidence intervals (CI). Statistical analyses were performed using the SPSS statistical package (Version 12.0J for Windows; SPSS, Chicago, Ill., USA), and a $\mathrm{p}$ value of less than 0.05 was regarded as statistically significant for each test.

\section{Results}

\section{Demographic Data}

Table 1 summarizes the baseline characteristics of the non-smoker, ex-smoker and current smoker groups. In 275 males, 186 individuals (68\%) were either current smokers or ex-smokers, and unexpectedly the systolic blood pressure was lower in male ex-smokers than in male non-smokers. On the other hand, 374 (90\%) of 415 females were non-smokers. Female current smokers tended to consume alcohol more frequently than non-smokers. Body mass index and total cholesterol levels were significantly lower in current smokers than in non-smokers. In each gender, the other variables were no different among the 3 groups.

\section{Smoking Status and Mortality}

During the 4-year observation period, 58 males and 50 females died. The main cause of death included malignant neoplasm (17 males and 11 females), cardiovascular diseases (CVD; 9 males and 19 females) and respiratory illnesses ( 21 males and 7 females). Other causes of death 
Table 1. Baseline characteristics of the participants according to their smoking status

\begin{tabular}{|c|c|c|c|c|c|c|}
\hline & \multicolumn{3}{|l|}{ Males } & \multicolumn{3}{|l|}{ Females } \\
\hline & $\begin{array}{l}\text { non-smokers } \\
(\mathrm{n}=89)\end{array}$ & $\begin{array}{l}\text { ex-smokers } \\
(\mathrm{n}=124)\end{array}$ & $\begin{array}{l}\text { current smokers } \\
(\mathrm{n}=62)\end{array}$ & $\begin{array}{l}\text { non-smokers } \\
(\mathrm{n}=374)\end{array}$ & $\begin{array}{l}\text { ex-smokers } \\
(\mathrm{n}=14)\end{array}$ & $\begin{array}{l}\text { current smokers } \\
(\mathrm{n}=27)\end{array}$ \\
\hline Current drinkers, $\mathrm{n}$ & $38(42.7)$ & $58(46.8)$ & $27(43.5)$ & $58(15.5)$ & $1(7.1)$ & $9(33.3)^{b}$ \\
\hline Body mass index & $22.9 \pm 0.3$ & $22.4 \pm 0.3$ & $21.9 \pm 0.4$ & $22.9 \pm 0.2$ & $22.1 \pm 0.9$ & $21.2 \pm 0.6^{\mathrm{b}}$ \\
\hline Systolic blood pressure, $\mathrm{mm} \mathrm{Hg}$ & $154.3 \pm 2.3$ & $145.1 \pm 2.0^{\mathrm{a}}$ & $148.6 \pm 3.0$ & $152.1 \pm 1.3$ & $153.8 \pm 6.7$ & $147.1 \pm 4.7$ \\
\hline Diastolic blood pressure, $\mathrm{mm} \mathrm{Hg}$ & $80.2 \pm 1.3$ & $77.8 \pm 1.0$ & $79.2 \pm 1.5$ & $79.1 \pm 0.7$ & $78.5 \pm 3.7$ & $76.0 \pm 2.5$ \\
\hline Pulse rate, beats $/ \mathrm{min}$ & $69.1 \pm 1.9$ & $67.5 \pm 1.0$ & $71.6 \pm 1.0$ & $71.8 \pm 0.6$ & $70.1 \pm 3.0$ & $70.6 \pm 1.8$ \\
\hline $\mathrm{ADL}$ - dependent, $\mathrm{n}$ & $6(6.7)$ & $8(6.5)$ & $6(9.7)$ & $21(5.6)$ & $1(7.1)$ & $4(14.8)$ \\
\hline Total cholesterol, $\mathrm{mmol} / \mathrm{l}$ & $5.00 \pm 0.10$ & $4.86 \pm 0.07$ & $4.75 \pm 0.11$ & $5.65 \pm 0.05$ & $5.82 \pm 0.25$ & $5.16 \pm 0.21^{b}$ \\
\hline Blood glucose, mmol/l & $6.82 \pm 0.26$ & $7.45 \pm 0.30$ & $6.77 \pm 0.42$ & $6.61 \pm 0.15$ & $6.01 \pm 0.69$ & $6.01 \pm 0.14$ \\
\hline
\end{tabular}

Figures in parentheses are percentages. ${ }^{\mathrm{a}} \mathrm{p}<0.05$ ex-smokers vs. non-smokers, ${ }^{\mathrm{b}} \mathrm{p}<0.05$ current smokers vs. non-smokers.
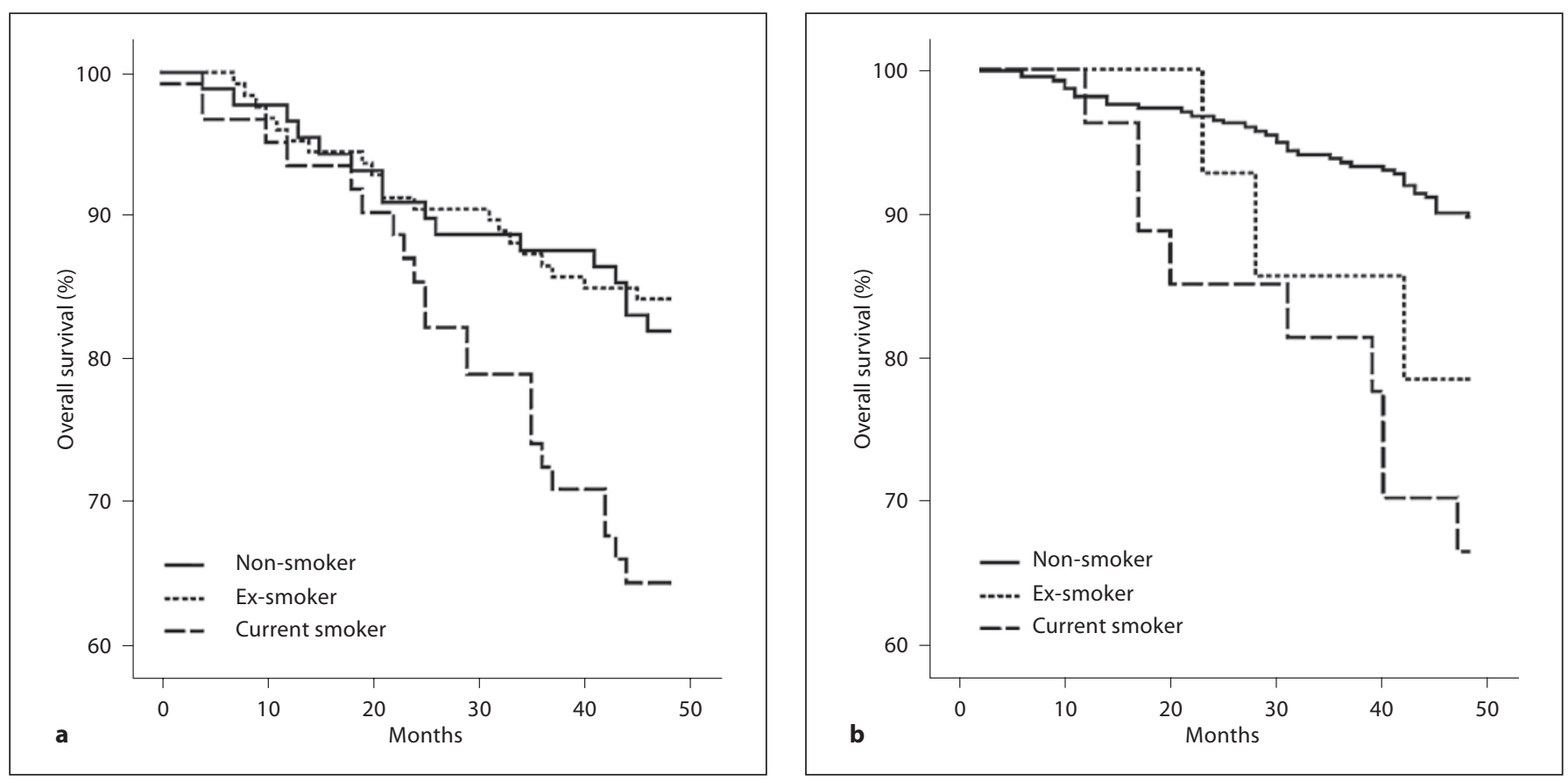

Fig. 1. Comparison of overall survival according to smoking status. a In male participants, the cumulative survival rate in the group of current smokers was the lowest among the 3 groups. The rates were comparable in the remaining 2 groups. b In female participants, the cumulative rate in the group of non-smokers was the most favourable among the 3 groups.

were digestive tract bleeding ( 1 male and 3 females), accidents (4 males), liver cirrhosis ( 2 males and 1 female), autoimmune disease ( 1 male and 1 female), soft tissue tumour ( 1 male and 1 female), suicide ( 2 females), multiple myeloma (1 male), carbon monoxide poisoning (1 male) and chronic renal failure ( 1 female). In the remaining 4 patients, we could not ascertain the cause of death from the register.

Figure 1 compares the overall survival among the 3 groups. In the male participants, the cumulative survival rate in current smokers was the lowest $(\mathrm{p}<0.01)$, while the rate was similar in non-smokers and ex-smokers 
Table 2. Adjusted RR for mortality according to smoking status

\begin{tabular}{|c|c|c|c|c|c|c|}
\hline & Person-years & $\begin{array}{l}\text { Mortality } \\
\mathrm{n} / 1,000 \\
\text { person-years }\end{array}$ & Overall risk & $\begin{array}{l}\text { Risk of } \\
\text { malignant } \\
\text { neoplasm }\end{array}$ & Risk of CVD & $\begin{array}{l}\text { Risk of } \\
\text { respiratory } \\
\text { illness }\end{array}$ \\
\hline \multicolumn{7}{|l|}{ Men } \\
\hline Non-smoker & 326.5 & 49.0 & 1.0 & 1.0 & 1.0 & 1.0 \\
\hline Ex-smoker & 454.7 & 44.0 & $1.1(0.5-2.4)$ & $3.5(0.4-30.3)$ & $0.1(0.0-1.8)$ & $1.5(0.4-5.7)$ \\
\hline Current smoker & 209.1 & 105.2 & $2.3(1.0-5.2)^{\mathrm{a}}$ & $10.7(1.3-90.8)^{\mathrm{a}}$ & $0.9(0.1-6.5)$ & $1.5(0.3-6.7)$ \\
\hline \multicolumn{7}{|l|}{ Women } \\
\hline Non-smoker & $1,436.3$ & 26.5 & 1.0 & 1.0 & 1.0 & 1.0 \\
\hline Ex-smoker & 51.8 & 58.0 & $2.1(0.6-7.0)$ & - & $1.8(0.2-13.9)$ & $11.6(1.9-68.7)^{\mathrm{b}}$ \\
\hline Current smoker & 93.9 & 95.8 & $4.2(1.9-9.5)^{\mathrm{c}}$ & $3.0(0.6-14.9)$ & $5.2(1.6-16.9)^{\mathrm{d}}$ & - \\
\hline
\end{tabular}

Numbers in parentheses indicate a 95\% CI. ${ }^{a} \mathrm{p}<0.05$ current smokers vs. non-smokers, ${ }^{\mathrm{b}} \mathrm{p}<0.01$ ex-smokers vs. non-smokers, ${ }^{\mathrm{c}} \mathrm{p}<0.005$ current smokers vs. non-smokers, ${ }^{\mathrm{d}} \mathrm{p}<0.01$ current smokers vs. non-smokers; $-=$ not available because of small numbers in the sample.

(non-smokers vs. ex-smokers: $\mathrm{p}=0.75$, non-smokers vs. current smokers: $p=0.02$, ex-smokers vs. current smokers: $\mathrm{p}<0.005$; fig. 1a). The mortality rates during the 4 years following the baseline were $18.6 \%$ in non-smokers, $16.3 \%$ in ex-smokers and $35.5 \%$ in current smokers. In females, the cumulative survival rate was the most favourable in non-smokers $(\mathrm{p}<0.001$; non-smokers vs. exsmokers: $\mathrm{p}=0.17$, non-smokers vs. current smokers: $\mathrm{p}<$ 0.001, ex-smokers vs. current smokers: $p<0.42$; fig. $1 b$ ). The mortality rates during the 4 -year period after the baseline were $10.2 \%$ in non-smokers, $21.4 \%$ in ex-smokers and $33.3 \%$ in current smokers. However, the small number of subjects among the female current and exsmokers did not allow a statistical comparison of the rate between the 2 groups.

Table 2 shows the relative risks of mortality in exsmokers and current smokers when compared to nonsmokers. The RR was adjusted by ADL, body mass index, systolic blood pressure, total cholesterol level and fasting blood glucose level [16-20]. As shown in table 2, the RR of overall mortality in current smokers was significantly higher when compared to non-smokers in males (RR:2.3, 95\% CI: 1.0-5.2) and in females (RR: 4.2, 95\% CI: 1.9-9.5). In both genders, the RR of overall mortality in ex-smokers was not different from that of non-smokers.

In males, current smokers died of malignant neoplasms more frequently than non-smokers (RR: 10.7, 95\% CI: 1.3-90.8). On the other hand, smoking status did not affect the mortality caused by CVD or respiratory illness. In females, the mortality due to CVD was higher in current smokers than in non-smokers (RR: 5.2, 95\% CI: 1.6-
Table 3. Comparison of adjusted RR of mortality in male current smokers according to the number of cigarettes per day

\begin{tabular}{lcll}
\hline & Person-years & $\begin{array}{l}\text { Mortality } \\
\mathrm{n} / 1,000 \\
\text { person-years }\end{array}$ & $\begin{array}{l}\text { Overall } \\
\text { risk }\end{array}$ \\
\hline $\begin{array}{l}\text { Non-smoker } \\
\text { Daily amount of cigarettes } \\
\leq 20\end{array}$ & $\begin{array}{c}173.3 \\
>20\end{array}$ & 326.5 & 1.0 \\
\hline
\end{tabular}

Numbers in parentheses indicate a 95\% CI. ${ }^{a} \mathrm{p}<0.05$.

16.9). Similarly, the mortality due to respiratory illness was higher in ex-smokers than non-smokers (RR: 18.1, 95\% CI: 2.9-112.7). However, the small number of females did not allow statistical analyses between current smokers and non-smokers.

\section{Effect of Smoking Dose and Periods of Smoking \\ Cessation on Mortality}

In male current smokers, the possible relationship between the daily amount of consumed cigarettes and overall mortality was tested (table 3). Among 62 current smokers, 50 individuals smoked 20 cigarettes or less per day and 12 individuals smoked over 20 cigarettes per day. While the increase in RR of overall mortality in the latter subjects (RR: 4.1, 95\% CI: 1.4-12.4) against non-smokers was statistically significant, there was no such signifi- 
Table 4. Comparison of adjusted RR for mortality in male exsmokers according to the age at which they stopped smoking

\begin{tabular}{lcll}
\hline & $\begin{array}{l}\text { Person- } \\
\text { years }\end{array}$ & $\begin{array}{l}\text { Mortality } \\
\mathrm{n} / 1,000 \\
\text { person-years }\end{array}$ & $\begin{array}{l}\text { Overall } \\
\text { risk }\end{array}$ \\
\hline $\begin{array}{l}\text { Non-smoker } \\
\text { Age at cessation of smoking } \\
\quad<65 \text { years }\end{array}$ & $\begin{array}{l}\text { 281.7 } \\
\geq 65 \text { years }\end{array}$ & 326.5 & 1.0 \\
\hline
\end{tabular}

Numbers in parentheses indicate a $95 \%$ CI.

cance in the former subjects (RR: 2.2, 95\% CI: 0.9-5.3). RR for cause-specific mortalities were not significantly increased in either group of subjects.

Among 124 male ex-smokers, 75 individuals had stopped smoking by the age of 64 and the remaining 49 individuals after the age of 65 . When these 2 subgroups were compared, the RR of overall mortality against nonsmokers was higher in the latter subgroup (RR: 1.5, 95\% CI: $0.6-3.7)$ than in the former one (RR: $0.7,95 \%$ CI: $0.3-$ 2.0; table 4). However, neither the increase in RR for overall mortality nor the cause-specific mortalities were statistically significant in each subgroup.

\section{Discussion}

Based upon the unequivocal improvement of life expectancy in young or middle-aged ex-smokers when compared to current smokers [21,22], the cessation of smoking has been generally recommended to all smokers. However, it still remains to be elucidated whether the cessation of smoking can improve life expectancy in oldaged smokers as well. Previous reports showed the association of smoking status with mortality in old-aged populations divided by age into 10-year categories [23-25]. However, when examining an old-age population it seems critical to minimize the range of ages because only a small increase in life would be expected in that generation. We thus recruited elderly people of exactly the same age for the present study.

In the present study, we could show that the RR of overall mortality in current smokers compared to nonsmokers was 2.3 in males and 4.2 in females. In addition, there was a positive correlation between daily consumption of cigarettes and overall mortality in male smokers.
These results suggest that smoking has a significant impact on overall mortality in a Japanese old-aged population. On the other hand, previous investigations have shown habitual smoking to increase the overall mortality by $10-70 \%$ in old-aged populations $[23,24,26,27]$. Such differences in the impact of smoking may be partly explained by differences in life expectancy among the cohorts examined. For example, the overall mortality of non-smokers in American community residents over 75 years of age has been reported to be 90.1/1,000 personyears in males and 62.4/1,000 person-years in females [23], the values of which were much greater than those of the non-smokers of the present study. Since Japanese people have the second longest life expectancy in the world, the harm caused by habitual smoking might be amplified in our country.

Van de Mheen and Gunning-Schepers [28] previously reported that the wide variation in $\mathrm{RR}$ associated with smoking is partly explained by misclassification of smoking status, heterogeneity in the duration of the follow-up periods and differences in the amount of smoking among populations. In the present study, precise information concerning the smoking status was collected by interviewers in order to minimize bias in the interpretation of data. Therefore, the possibility that smoking status was misclassified seems negligible. However, we could calculate mortalities for only a 4 -year period because the recruitment of old-aged participants caused frequent deaths within a shorter duration. Accordingly, the particular biological characteristics of the cohort, especially advanced age, seem to have contributed to the difference in the RR of the present study.

Among cause-specific mortalities, the RR for mortality from malignant neoplasm in males was significantly higher in current smokers than in non-smokers. While it has been shown that the mortality from malignant neoplasms is higher in Japanese males than in western males [29], such a difference may have been a consequence of habitual smoking. In contrast, the RR for CVD or respiratory illness were not different between our current smokers and non-smokers. Although morbidities from CVD or respiratory illness were not investigated, both CVD and respiratory illness had no influence on mortality in male Japanese old-aged smokers.

It has been reported that habitual smoking is the single biggest risk for developing CVD in females [23, 24, 30], and that the incidence of CVD apparently increases in postmenopausal females [31]. Moreover, the toxic effects of smoking on the coronary artery have been indicated to be more evident in females than in males [32]. Although 
the sample size was small, the higher RR for CVD in our female smokers suggests that Japanese females are at a high risk of atherosclerotic change by smoking.

In our male ex-smokers, the RR of overall mortality was lower in individuals who quit smoking by the age of 65 than in the other individuals. Although the difference did not reach statistical significance, the observation is consistent with the previous reports, which dealt with middle-aged long-term quitters [13, 22]. Although the small number of subjects did not allow statistical analysis, the RR of mortality was, at least, higher in female current smokers than in female ex-smokers. Considering these observations, it seems likely that the improvement in the risk of mortality is anticipated by an early cessation of smoking even in old-aged smokers. Further study is necessary to clarify whether early cessation of smoking in old-aged smokers decreases mortality.

There were several limitations to our study. First, the sample size, especially for female ex-smokers and current smokers, was small for statistical analyses, therefore re- sulting in a low level of statistical power. Second, there might have been a selection bias, because our survey was based on only $54 \%$ of subjects initially invited. In addition, all participants were presumed to have been healthy individuals who could participate in face-to-face interviews. Thus, the cohort may not be representative of the general Japanese population at 80 years of age. Third, we could not assess the effect of the cessation of smoking after the baseline assessment because we did not have direct or indirect contact afterwards. Finally, there may be some differences between the descriptions of causes of death, because the data were extracted from the Public Health Register. In fact, the cause of death could not be specified in 4 individuals.

In conclusion, since the present study demonstrated that habitual smoking contributes to higher mortality, even in an old-aged Japanese population, it seems reasonable to advise smokers to stop smoking. There are health benefits to stopping smoking as early as possible.

\section{References}

-1 Sterling TD, Rosenbaum WL, Weinkam JJ: Risk attribution and tobacco-related deaths. Am J Epidemiol 1993;138:128-139.

$\checkmark 2$ Wald NJ, Watt HC: Prospective study of effect of switching from cigarettes to pipes or cigars on mortality from three smoking related diseases. BMJ 1997;314:1860-1863.

-3 Enstrom JE: Smoking cessation and mortality trends among two United States populations. J Clin Epidemiol 1999;52:813-825.

-4 Akiba S, Hirayama T: Cigarette smoking and cancer mortality risk in Japanese men and women: results from reanalysis of the sixprefecture cohort study data. Environ Health Perspect 1990;87:19-26.

5 Sasco AJ: Tobacco and cancer: how to react to the evidence. Eur J Cancer Prev 1992;1: 367-373.

-6 Sankaranarayanan R, Masuyer E, Swaminathan R, Ferlay J, Whelan S: Head and neck cancer: a global perspective on epidemiology and prognosis. Anticancer Res 1998; 18: 4779-4786.

7 Shinton R, Beevers G: Meta-analysis of relation between cigarette smoking and stroke. BMJ 1989;298:789-794.

-8 Prescott E, Scharling H, Osler M, Schnohr P: Importance of light smoking and inhalation habits on risk of myocardial infarction and all cause mortality: a 22 year follow-up of 12,149 men and women in the Copenhagen City Heart Study. J Epidemiol Community Health 2002;56:702-706.
-9 Leone A, Giannini D, Bellotto C, Balbarini A: Passive smoking and coronary heart disease. Curr Vasc Pharmacol 2004;2:175-182.

$\checkmark 10$ Ambrose JA, Barua RS: The pathophysiology of cigarette smoking and cardiovascular disease: an update. J Am Coll Cardiol 2004;43: 1731-1737.

11 Vial WC: Cigarette smoking and lung disease. Am J Med Sci 1986;291:130-142.

12 Sherman CB: The health consequences of cigarette smoking: pulmonary diseases. Med Clin North Am 1992;76:355-375.

13 Pelkonen M, Notkola IL, Tukiainen H, Tervahauta M, Tuomilehto J, Nissinen A: Smoking cessation, decline in pulmonary function and total mortality: a 30 year follow-up study among the Finnish cohorts of the Seven Countries Study. Thorax 2001;56:703-707.

14 Matsumura K, Ansai T, Awano S, Hamasaki T, Akifusa S, Takehara T, Abe I, Takata Y: Association of body mass index with blood pressure in 80-year-old subjects. J Hypertens 2001;19:2165-2169.

15 Takata Y, Ansai T, Fukuhara M, Sonoki K, Wakisaka M, Fujisawa K, Akifusa S, Takehara T: Chewing ability and quality of life in an 80-year-old population. J Oral Rehabil 2006;33:330-334.
16 Blair SN, Wei M: Sedentary habits, health, and function in older women and men. Am J Health Promot 2000;15:1-8.

17 Seccareccia F, Lanti M, Menotti A, Scanga M: Role of body mass index in the prediction of all cause mortality in over 62,000 men and women. The Italian RIFLE Pooling Project. Risk Factor and Life Expectancy. J Epidemiol Community Health 1998;52:20-26.

18 Psaty BM, Furberg CD, Kuller LH, Cushman M, Savage PJ, Levine D, O'Leary DH, Bryan RN, Anderson M, Lumley T: Association between blood pressure level and the risk of myocardial infarction, stroke, and total mortality: the cardiovascular health study. Arch Intern Med 2001;161:1183-1192.

19 Iribarren C, Sharp D, Burchfiel CM, Sun P, Dwyer JH: Association of serum total cholesterol with coronary disease and all-cause mortality: multivariate correction for bias due to measurement error. Am J Epidemiol 1996;143:463-471.

20 Sinclair AJ, Robert IE, Croxson SC: Mortality in older people with diabetes mellitus. Diabet Med 1997;14:639-647.

21 Hallstrom AP, Cobb LA, Ray R: Smoking as a risk factor for recurrence of sudden cardiac arrest. N Engl J Med 1986;314:271-275.

-22 Doll R, Peto R, Boreham J, Sutherland I: Mortality in relation to smoking: 50 years' observations on male British doctors. BMJ 2004;328:1519. 
-23 LaCroix AZ, Lang J, Scherr P, Wallace RB, Cornoni-Huntley J, Berkman L, Curb JD, Evans D, Hennekens CH: Smoking and mortality among older men and women in three communities. N Engl J Med 1991;324:16191625.

-24 Vogt MT, Cauley JA, Scott JC, Kuller LH, Browner WS: Smoking and mortality among older women: the study of osteoporotic fractures. Arch Intern Med 1996;156:630-636.

-25 Doll R, Peto R, Wheatley K, Gray R, Sutherland I: Mortality in relation to smoking: 40 years' observations on male British doctors. BMJ 1994;309:901-911.
26 Ho SC, Zhan SY, Tang JL, Chan SG, Woo J: Smoking and mortality in an older Chinese cohort. J Am Geriatr Soc 1999;47:14451450 .

27 Abramson JH: The hazard of persistent cigarette smoking in later life. Am J Med Sci 1977;274:35-43.

28 van de Mheen PJ, Gunning-Schepers LJ: Differences between studies in reported relative risks associated with smoking: an overview. Public Health Rep 1996;111:420-426.

29 Nakaji S, MacAuley D, O’Neill S, McNally O, Baxter D, Sugawara K: Life expectancies in the United Kingdom and Japan. J Public Health Med 2003;25:120-124.
30 Iso H, Date C, Yamamoto A, Toyoshima H, Watanabe Y, Kikuchi S, Koizumi A, Wada Y, Kondo T, Inaba Y, Tamakoshi A, JACC Study Group: Smoking cessation and mortality from cardiovascular disease among Japanese men and women: the JACC Study. Am J Epidemiol 2005;161:170-179.

31 Mosca L: The role of hormone replacement therapy in the prevention of postmenopausal heart disease. Arch Intern Med 2000;160: 2263-2272.

32 Pope M, Ashley MJ, Ferrence R: The carcinogenic and toxic effects of tobacco smoke: are women particularly susceptible? J Gend Specif Med 1999;2:45-51. 